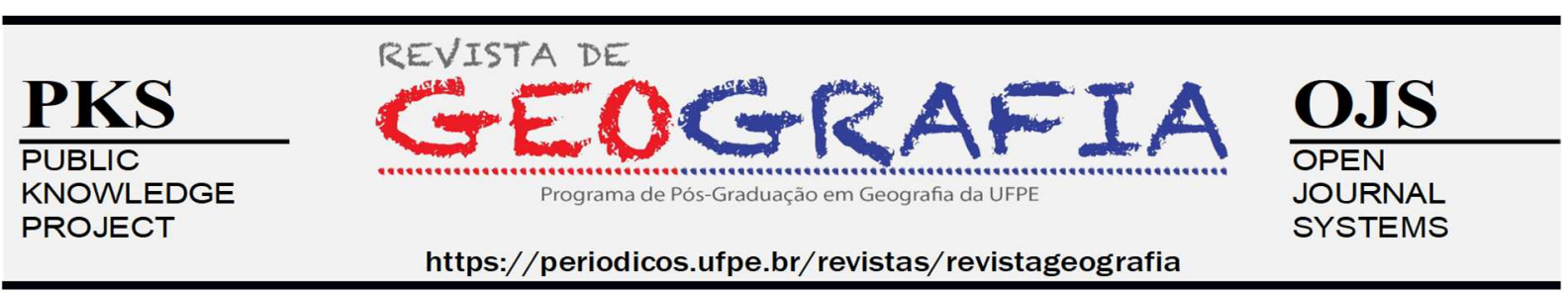

\title{
PANORAMA DA PRODUÇÃO CIENTÍFICA SOBRE A REDUÇÃO DE RISCOS DE DESASTRES NO ESTADO DO PARANÁ
}

Fernanda Enko dos Santos Batista ${ }^{1}$, Murilo Noli da Fonseca ${ }^{2}$, Larissa Maria da Silva Ferentz ${ }^{3}$, Eduardo Gomes Pinheiro ${ }^{4}$, Danyelle Stringari ${ }^{5}$

1 Bacharel em Ciências Biológicas, Fundação de Pesquisas Florestais do Paraná. E-mail: fernandaenko1@gmail.com, https://orcid.org/0000-0002-4249-3531

2 Mestre e Doutorando em Gestão Urbana, Pontifícia Universidade Católica do Paraná (PUCPR). E-mail: murilonoli@gmail.com, https://orcid.org/0000-0002-0718-3087

3 Mestre e Doutorando em Gestão Urbana, Pontifícia Universidade Católica do Paraná (PUCPR). E-mail: ferentzengenharia@gmail.com, https://orcid.org/0000-0001-5804-0361

${ }^{4}$ Doutor em Gestão Urbana, Corpo de Bombeiros do Estado do Paraná. E-mail: egopinheiro@hotmail.com, https://orcid.org/0000-0001-5408-7883

5 Doutora em Genética, Universidade Estadual do Paraná (Unespar). E-mail: danystringari@gmail.com, https://orcid.org/0000-0002-3532-7914

Artigo recebido em 18/08/2020 e aceito em 18/06/2021

\section{RESUMO}

Esse estudo teve como objetivo a sistematização dos artigos produzidos por instituições de ensino e pesquisa do Estado do Paraná, referentes à temática de Redução de Riscos de Desastres. A pesquisa foi desenvolvida por meio de buscas em bancos de dados, como o Portal Capes, por palavras-chave contidas nas classificações COBRADE (Classificação e Codificação Brasileira de Desastres) e CODAR (Codificação de Desastres, Ameaças e Riscos). Foram analisados 581 artigos, pertencentes a 124 periódicos. Como resultado, a cronologia demonstrou que desde a primeira publicação, em 1970, há um aumento significativo de pesquisas nesta área a partir dos anos 2000, com maior pico em 2012. Além disto, os artigos encontrados foram subdivididos por palavras-chave, classificados e disponibilizados no Portal da Redesastre, com o intuito de facilitar o acesso para novos pesquisadores.

Palavras-chave: Riscos; Desastres; COBRADE; CODAR.

\section{BIBLIOGRAPHIC INVENTORY OF ACADEMIC-SCIENTIFIC PRODUCTION IN PARANÁ IN THE AREA OF DISASTER RISK REDUCTION}

\section{ABSTRACT}

This study aimed to systematize the articles produced by teaching and research institutions in the state of Paraná, related to the theme of Disaster Risk Reduction. The research was developed through searches in databases, such as Portal Capes, for keywords contained in the classifications COBRADE and CODAR. A total of 581 articles from 124 journals were analyzed. As a result, chronology has shown that since the first publication in 1970 there has been a significant increase in research in this 
area since the 2000s, with the highest peak in 2012. In addition, the articles found were subdivided by keywords, available in the Redesastre Portal, in order to facilitate access for new researchers.

Keywords: Risks; Disasters; COBRADE; CODAR.

\section{INTRODUÇÃO}

Os desastres resultam da ação de eventos perigosos que ocorrem em certa área geográfica, sobretudo com condições sociais vulneráveis (como resultado de consequências cumulativas de decisões - sejam elas individuais e/ou coletivas - previamente adotadas, ligadas à organização e ao planejamento do território), durante um período de tempo, culminando na destruição da morfologia de uma comunidade e sobrepujando a resiliência de tal (WORLD BANK; UNITED NATIONS, 2010). A sua intensidade depende da interação entre a magnitude do evento adverso e o grau de vulnerabilidade do sistema receptor afetado, sendo que este último é visto como fator preponderante para a intensificação de um desastre.

Entre 2000 e 2010, por exemplo, terremotos fizeram 680 mil vítimas fatais e quase metade dos casos ocorreram no Haiti. Em média, estima-se que aproximadamente 102 milhões de pessoas são afetadas por inundações a cada ano no mundo, 37 milhões por ciclones, furacões e tufões e 366 mil por deslizamentos (FREITAS et al., 2012). De acordo com o “Atlas Brasileiro de Desastres Naturais - 1991 a 2012”, houve um aumento no número de registros de desastres na década de 2000 onde, do total de 38.996 registros, aproximadamente $22 \%$ ocorreram na década de 1990; 56\% na década de 2000; e apenas nos anos de 2010, 2011 e 2012 este número já totaliza 22\% (FURTADO, 2012).

Mais especificamente no Paraná, os dados da Coordenadoria Estadual de Proteção e Defesa Civil (CEPDEC/PR) demonstram que no ano de 2017 houve um aumento de 45,65\% na quantidade dos registros de desastres no Estado em relação ao ano anterior. Em compensação, o número de afetados apresentou redução de quase $50 \%$ comparada ao registrado em 2016 (CEPDEC, 2018). Esses impactos afetam de forma distinta os grupos sociais. Diversos fatores, como o nível de renda, grupo populacional, idade, escolaridade e habitação podem alterar a predisposição às ocorrências dos danos e perdas ocasionados por esses eventos. Logo, estudos são necessários para que os fenômenos agregados aos desastres naturais sejam compreendidos e proporcionar um planejamento na prevenção desses eventos.

Diante desta problemática, a busca por informações sobre desastres tornou-se uma das principais prioridades. No Paraná não há até o momento nenhum levantamento das publicações sobre o tema. Dessa maneira, o objetivo do presente artigo compreende a 
estruturação do conhecimento produzido por instituições da Rede Estadual de Pesquisa, Ensino, Extensão e Inovação Tecnológica voltada à redução de riscos de desastres do Paraná (Redesastre), e também por instituições não cooperadas com a Redesastre, por meio de artigos e a partir disso, disponibilizá-los para consulta através de um portal de busca.

\section{O PAPEL DO INVENTÁRIO NA PRESERVAÇÃo DE MEMÓRIAS SOBRE DESASTRES}

Desde a antiguidade, a sociedade cria sistemas que a auxilia na organização e preservação de memórias. Os primeiros padrões encontrados são definidos como listas ou inventários, os quais continham fragmentos de títulos, descrições e localizações escritas em tábuas de argila (GARRIDO ARRILA, 1996; MEY; SILVEIRA, 2009; SILVA; SILVA, 2015). Por isto, os inventários podem ser considerados como o primeiro modelo usado para o surgimento de novas sistemáticas, como foi com o caso dos catálogos. No século XVI, o tipo de armazenamento de informações passou a apresentar características extras, com descrições bibliográficas, resultando em uma forma de conservar informações (SILVA; SILVA, 2015).

Tendo em vista a proximidade estrutural entre inventários e catálogos, é importante conceituá-los a fim de se deixar clara a sua diferenciação, pois ainda existe confusão entre os dois temas. A catalogação permite não só que seja realizada a identificação dos conteúdos, como também apresenta as relações dos itens do documento (LANCASTER, 2003). Segundo Mey (1995), o catálogo pode ser definido como um sistema de informações que consegue transmitir as mensagens dos itens dos documentos, seja em um ou mais acervos, de maneira estruturada e organizada. Em contrapartida, o inventário descreve o grupo de documentos, permitindo a apresentação de uma série histórica ou apenas da indicação de dados (BELlOTTO, 2004). Segundo Heredia Herrera (1991) o inventário descreve séries sistematizadas, as quais foram elaboradas e aperfeiçoadas com o decorrer dos anos pelas instituições que as criaram. Ou seja, enquanto a catalogação identifica informações individualizadas, o inventário apresenta as relações existentes entre diferentes acervos.

Considerando o elevado número de informações geradas todos os dias, o levantamento sistemático resultante do inventariado é essencial para identificar padrões e até mesmo a falta de informações que ainda podem ser produzidas. Este tipo de modelo pode ser adotado, já que "seu campo de ação será um documentário ou um arquivo completo ou seção de fundo. Seu objeto, a série. Suas triplas funções: controle para o arquivista, orientação e informação, primordial para o pesquisador” (HEREDIA HERRERA, 1991, p. 335). 
A construção de inventários na temática de riscos e desastres tem se apresentando cada vez mais necessária, com vistas no aumento da frequência de eventos extremos no dia-adia das cidades. É importante buscar por fontes de pesquisas já desenvolvidas, para compreender o que já foi estudado, aprofundar-se no que já é existente e só então, dar continuidade aos trabalhos. Por essa razão, a estruturação dessas informações deve apresentar “descrição de documentos, seu conteúdo, características e propósitos, e a organização destas descrições, para fazer destes documentos e de suas partes acessíveis às pessoas, buscando-os ou as mensagens que eles contêm" (ANDERSON, 1996, p. 337).

Vale lembrar que este tipo de inventariado lida com grandes números de informações, sendo necessária a seleção de dados de pesquisa. Esta seleção pode ser adotada com base nas legislações e padrões adotados pelo país, estado ou municípios em estudo. No Brasil, é possível obter categorizações por meio da Classificação e Codificação Brasileira de Desastres (COBRADE) e da Codificação de Desastres, Ameaças e Riscos (CODAR), sendo estes os instrumentos oficiais utilizados para a identificação dos tipos de desastres no país.

A COBRADE categoriza os desastres em naturais e tecnológicos. Em relação aos naturais, eles são subdivididos em 5 grupos: geológicos, hidrológicos, meteorológicos, climatológicos e biológicos; enquanto os tecnológicos são subdivididos em substâncias radioativas, produtos perigosos, incêndios urbanos, obras civis e transporte de passageiros e cargas não perigosas. É importante destacar que cada um destes grupos ainda possui subgrupos, tipos e subtipos que os auxiliam nas subdivisões e categorizações dos desastres.

A CODAR possui uma classificação um pouco diferente do COBRADE, categorizando os desastres como naturais, humanos e mistos. Os naturais são subdivididos em origem sideral, relacionados com a geodinâmica terrestre externa, geodinâmica terrestre interna e com desiquilíbrios na biocenose. Os humanos são subdivididos em natureza tecnológica, natureza social e de causas biológicas. E por último, os mistos são subdivididos em geodinâmica terrestre externa e geodinâmica terrestre interna. Assim como a COBRADE, cada um desses grupos apresenta novos itens de classificação.

Além das categorizações relacionadas aos tipos de desastres existentes, também é importante ressaltar que as ações que visam a redução dos riscos de desastres também podem ser enquadradas em etapas específicas (FERENTZ; FONSECA; PINHEIRO, 2018). A gestão prospectiva é exercida antes de o desastre ocorrer, com a prevenção, mitigação e preparação, enquanto a gestão corretiva é aplicada quando o evento está ocorrendo e após ele finalizar 
com a resposta, reabilitação e recuperação. Todo este conjunto é parte integrante da Gestão de Riscos de Desastres (FURTADO, 2012; NARVÁEZ; LAVELL; ORTEGA, 2009).

Destaca-se que a ocorrência de desastres causa diversos efeitos negativos se a população e os gestores locais não estiverem preparados para lidar com as situações (PINHEIRO et al., 2021). Por isto que as pesquisas que são desenvolvidas com esta temática podem auxiliar os gestores na identificação de medidas e ações que visem a minimização dos impactos. Não obstante, o registro de informações e de seu histórico evolutivo também se faz necessário para que novas tecnologias sejam desenvolvidas e que os erros do passado não sejam mais cometidos (FONSECA e GARCIAS, 2020; FONSECA e GARCIAS, 2021).

\section{METODOLOGIA}

O presente trabalho visou a criação de um inventário de artigos produzidos por instituições do Estado do Paraná, por meio do levantamento de artigos em bases de dados. Iniciando com o desk research, a pesquisa foi realizada nas seguintes bases: Portal de Periódicos Capes, Web of Science, Scopus, Pubmed, Redulac, Spell, Scielo, Medline e Bireme, no período de 1970 a 2018. Para tanto, empregou-se as palavras-chave da COBRADE e da CODAR, e outros termos afetos ao tema (Quadro 1), totalizando em 115 palavras-chave.

\begin{tabular}{|c|c|c|c|}
\hline \multicolumn{2}{|c|}{ Quadro 1 - Termos adicionados na pesquisa de artigos sobre desastres. } \\
\hline Risco & Leishmaniose & Derramamento de Óleo & Defesa Civil \\
\hline Hidrogeologia & Malária & Ciclones Tropicais & Escassez \\
\hline Recursos Hídricos & Tripanossomíase & Depredação do Solo & Amebíase \\
\hline Meningite & Mananciais & Intoxicação Exógena & Sarampo \\
\hline Geomedicina & Resiliência & Sistemas de Coleta de Lixo & Intensa Poluição \\
\hline Acidente & Criminalidade & Migrações desordenadas & Desastre \\
\hline Dengue & Chuva Ácida & Conflitos Religiosos/ Raciais & Catástrofe \\
\hline Febre Amarela & Guerras & Destruição da Flora e Fauna & Agrotóxicos \\
\hline
\end{tabular}

Fonte: os autores (2020)

As publicações selecionadas por palavras-chave foram lidas para primeira conferência, observando se a produção foi executada por alguma instituição de ensino e pesquisa do Paraná e se o assunto seria de fato sobre desastres, ameaças e riscos. Os artigos selecionados foram organizados em planilhas contendo informação como revista, instituição, título, autor, 
ano de publicação, área de estudo, área do conhecimento, palavras-chave, tipo do desastre e classificação Qualis.

Foram excluídos artigos duplicados, publicados em conferências, livros, capítulo de livros, patentes e séries. É importante destacar que foram selecionados os artigos disponibilizados de forma gratuita em língua portuguesa, inglesa ou espanhola. O tipo de desastre foi classificado conforme categorização do COBRADE e CODAR (Quadro 2).

Quadro 2 - Tipo de desastre para categorização dos artigos

\begin{tabular}{|c|c|c|c|c|c|}
\hline \multirow{5}{*}{ Naturais } & Geológicos & \multirow{5}{*}{ Tecnológicos } & Produtos Perigosos & \multirow{5}{*}{ Sociais } & \multirow{2}{*}{$\begin{array}{c}\text { Convulsões } \\
\text { Sociais }\end{array}$} \\
\hline & Hidrológicos & & Produtos Radioativos & & \\
\hline & Meteorológicos & & Incêndios & & \multirow{3}{*}{$\begin{array}{c}\text { Conflitos } \\
\text { Bélicos }\end{array}$} \\
\hline & Climatológicos & & Obras Civis & & \\
\hline & Biológicos & & Transporte & & \\
\hline \multicolumn{6}{|c|}{ Mistos } \\
\hline
\end{tabular}

Fonte: COBRADE e CODAR, adaptado (2020).

Embora o tipo de desastre "misto" não possua nenhum subgrupo, ele considera os elementos da CODAR quanto a eventos relacionados à geodinâmica da Terra de forma externa e interna, como as chuvas ácidas, o efeito estufa e a salinização do solo. Com o encerramento do levantamento das pesquisas, foram feitas as estatísticas e gráficos por meio do programa Microsoft Excel, os quais são apresentados nas análises geral e bibliométrica.

\section{RESULTADOS E DISCUSSÕES ANÁLISE GERAL}

Como resultado do processo de levantamento de publicações, foram selecionados 581 artigos. Estes integram um total de 124 periódicos, dos quais a "Revista Ambiência" é aquela com o maior volume de publicações sobre riscos, ameaças e desastres no Estado do Paraná, totalizando 36 artigos (Figura 1). Ela é uma revista eletrônica, cuja periodicidade de publicação é quadrimestral, e tem como foco as áreas de ciências agrárias e ambientais. 
Figura 1 - Revistas eletrônicas que mais publicaram sobre a temática

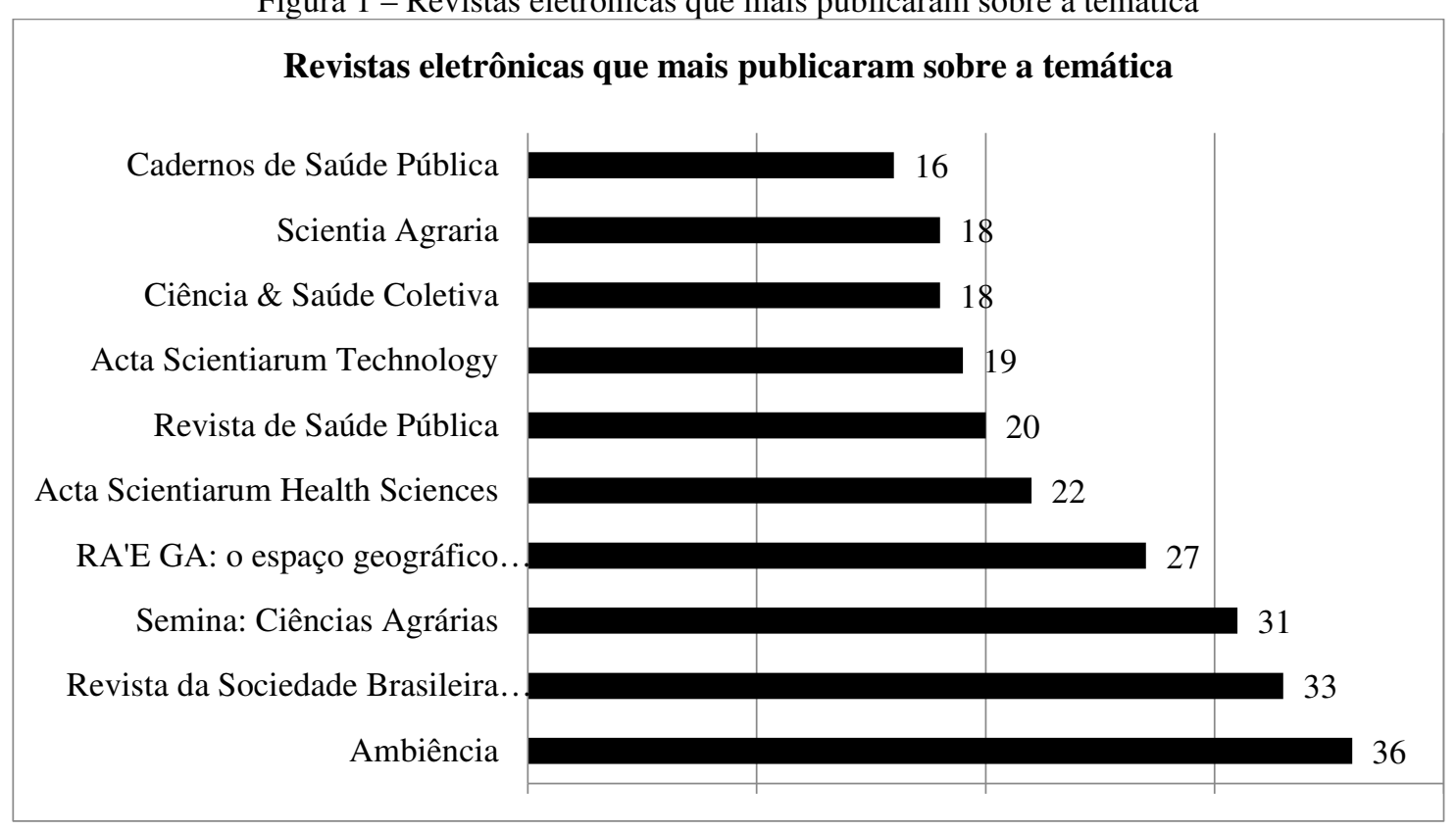

Fonte: os autores (2020)

No que tange às instituiçõos de ensino e pesquisa das quais os autores integram, levantou-se 35 instituições, dos quais 16 são públicas e 19 privadas. Mas, quando analisadas a partir do total de publicações, as instituições públicas correspondem por 91,6\% do volume de artigos encontrados, o que corrobora a Clarivate Analytics (2017), de que a produção científica no país depende unicamente destas instituições. Neste caso, verifica-se que dentre as 10 instituições com mais artigos publicados há o predomínio de instituições estaduais. Todavia, merece destaque a Universidade Federal do Paraná, que foi à instituição com o maior quantitativo de publicações (Figura 2). A primeira instituição privada neste ranking, a PUCPR, aparece em $7^{\mathrm{a}}$ lugar, com 90,7\% menos publicações do que a primeira colocada. 
Figura 2 - 10 instituições de ensino e pesquisa no Paraná com mais publicações sobre o tema

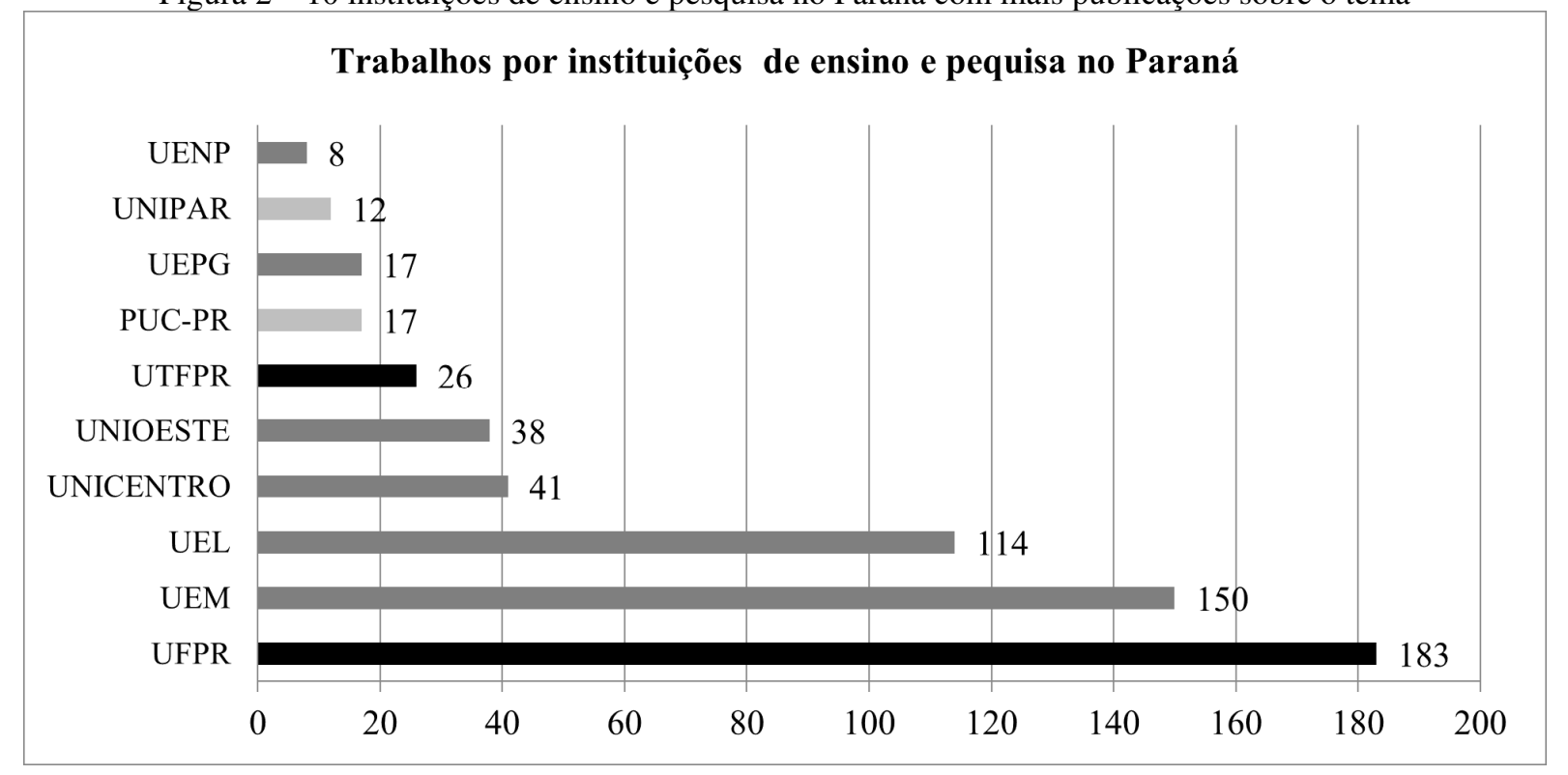

Fonte: os autores (2020)

A Rede Estadual de Pesquisa, Ensino, Extensão e Inovação Tecnológica voltada à redução de riscos e desastres no Estado do Paraná está instituída sob o Decreto Estadual $n^{\circ}$ 12445, de 24 de outubro de 2014. O propósito deste programa é a cooperação e intercâmbio da esfera tecnológica e científica direcionada à redução de riscos e desastres no estado. Diversas universidades públicas estaduais, federais e privadas estão envolvidas nesse processo através de um termo de cooperação (PINHEIRO et al., 2019). Dentre os artigos selecionados 95\% das instituições de ensino e pesquisa vinculadas aos artigos integram a Redesastre e tem o interesse de integrar esse conjunto de esforços que a temática requer.

As áreas de conhecimento que concentraram o maior número de publicações foram: Ciências da Saúde, Ciências Agrárias, Ciências Humanas e Ciências Biológicas (Figura 3). Quando desagregada tal informação, chega-se a seguinte configuração: a Geografia é a ciência com o maior quantitativo de artigos (78), seguido pela Medicina Veterinária (43), Análises Clínicas (32), Enfermagem (28), Ciências Animal (21) e Ciência da Saúde (21), Agronomia (18), Parasitologia (15), Engenharia Florestal (12) e Saúde Coletiva (11). 
Figura 3 - Classificação por área de conhecimento (CNPQ) dos artigos sobre desastres

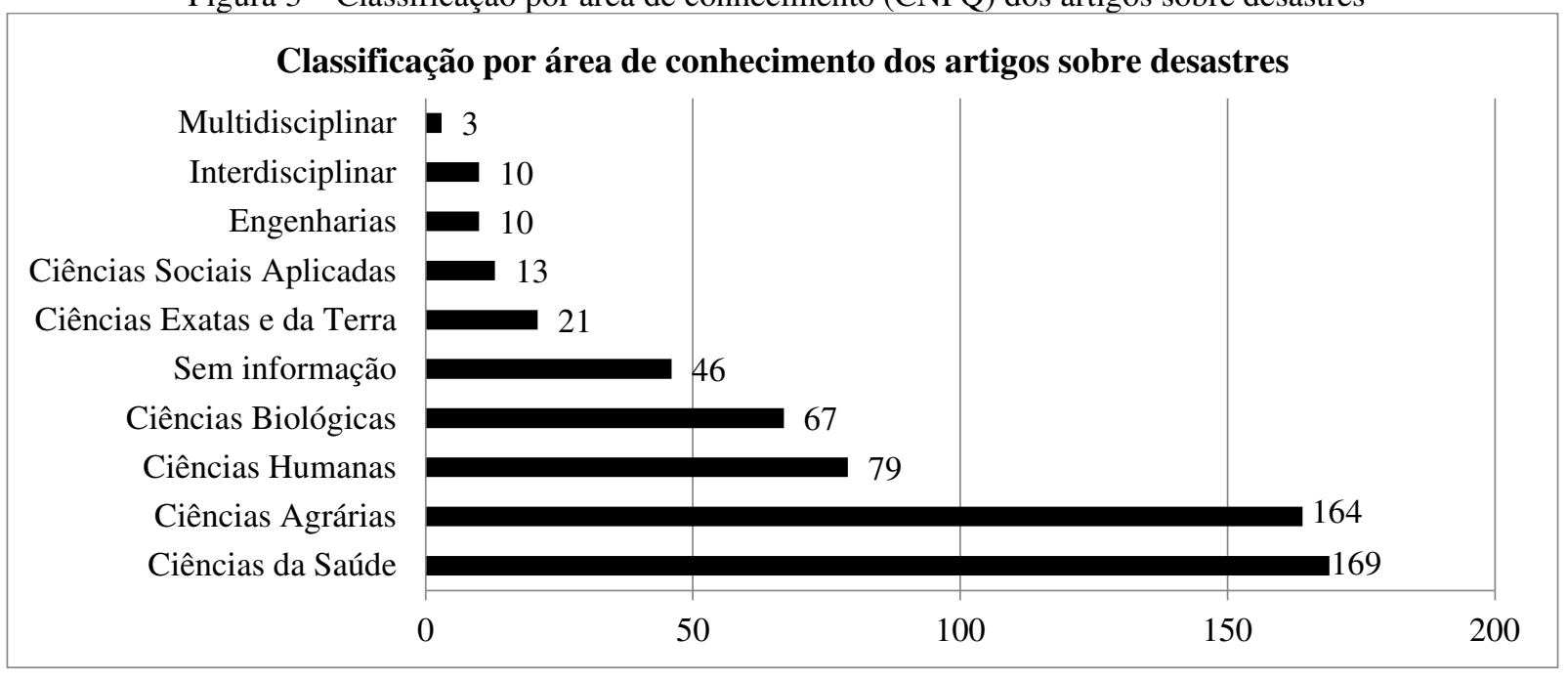

Fonte: os autores (2020)

Com relação à cronologia, as publicações iniciam em 1970 e possuem um aumento substancial a partir do ano 2000 (Figura 4). O primeiro trabalho encontrado foi de 1970, que versa sobre o "Tratamento da leishmaniose tegumentar americana pelo niridazolo", cuja autoria é de Miroslau Constante Baranski, da Universidade Estadual de Londrina. Cabe destacar que o ano de 2012 foi aquele em que houve o maior volume de publicações, totalizando 51. Tal fato pode ser explicado, além da maior visibilidade do tema nas mídias sociais, pelos eventos desastrosos que aconteceram no litoral do Paraná em 2011, os quais ficaram conhecidos como “Águas de Março”.

Figura 4 - Aspecto temporal das publicações sobre riscos, ameaças e desastres

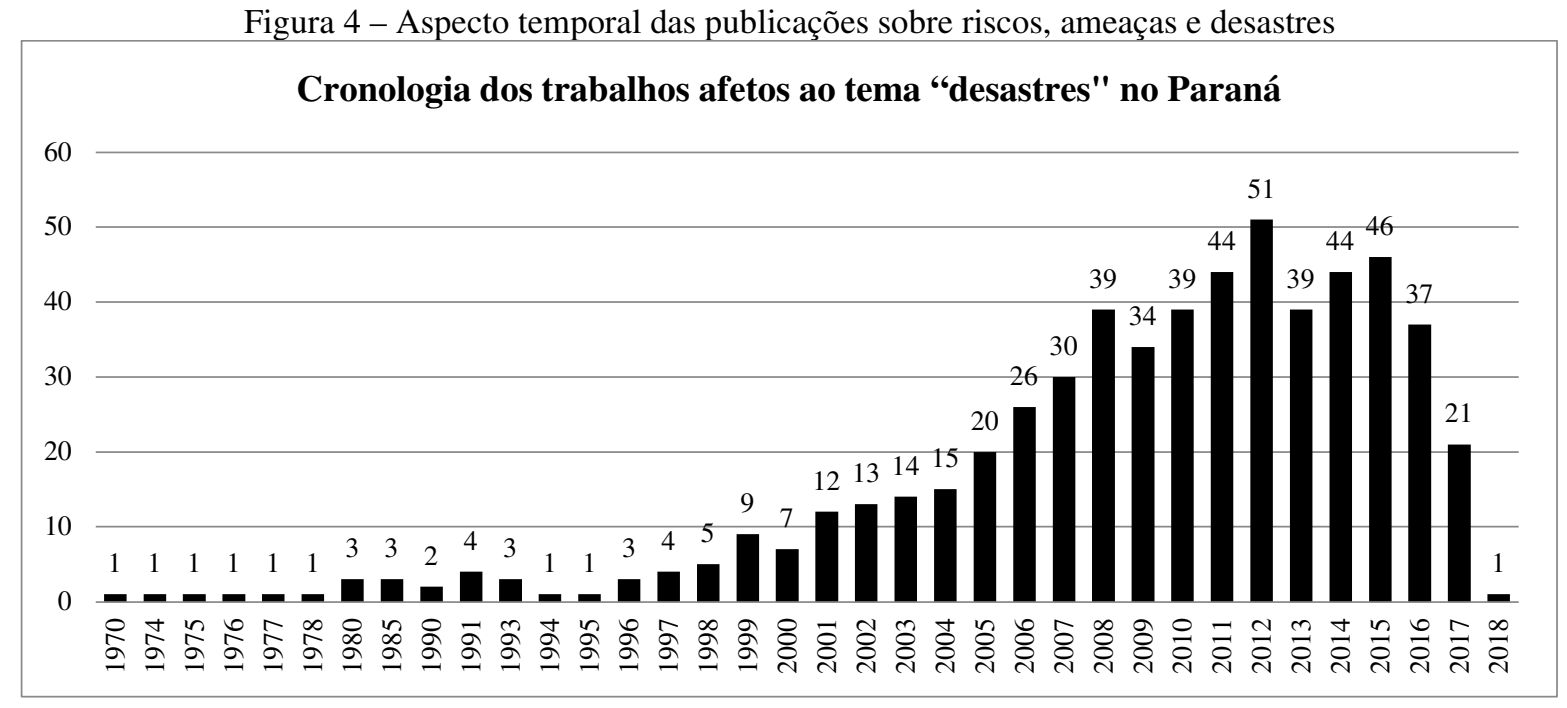

Fonte: os autores (2020) 
Do ponto de vista espacial houve distintas formas de abordagem, algumas analisando locais fora do Brasil (1\%), outras sobre o Brasil (1\%), outras abrangendo outros estados (6\%) e a maioria (84\%) contemplando algum território do Estado do Paraná. Destaca-se, ainda, os artigos que não possuem uma categoria de território analisado, o que corresponde a $8 \%$ das publicações selecionadas. Dentre os artigos sobre o Paraná, o município mais analisado foi Londrina com 71 publicações, seguido por Maringá com 70 artigos (Figura 5).

Figura 5 - Produções científicas afetas ao tema desastres no Estado do Paraná

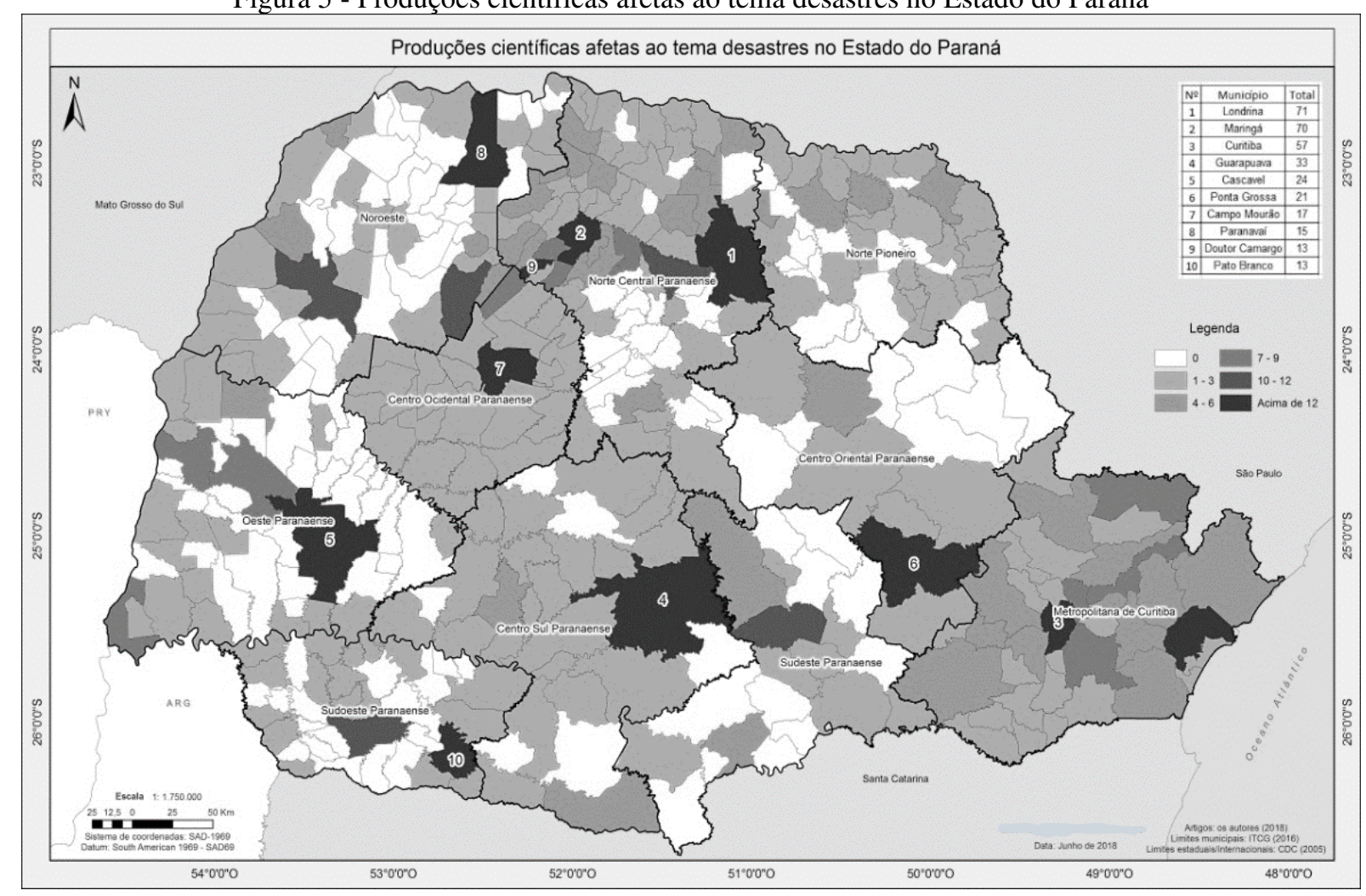

Fonte: os autores (2020)

Dos 10 municípios mais atingidos por eventos adversos no Paraná entre 1980 e 2017, conforme a Coordenadoria Estadual de Proteção e Defesa Civil (CEPDEC), apenas quatro não estão no grupo dos 10 municípios mais analisados nos artigos, a saber: São José dos Pinhais, Paranaguá, Araucária e Guaratuba. Tais municípios totalizaram 501 ocorrências, das quais 19 resultaram em declaração de Situação de Emergência, afetando 216.415 pessoas (CEPDEC, 2018). Os principais tipos de desastres que as atingem são: transporte de produtos perigosos rodoviário, vendavais, alagamentos, deslizamentos e colapso de edificação.

Por outro lado, quando analisado a partir das configurações dos desastres, temos o seguinte resultado: a maior parcela dos artigos trata dos desastres deflagrados por eventos naturais $(85,1 \%)$, sociais $(7,3 \%)$ e tecnológicos $(6,5 \%)$. Os mistos foram abordados em apenas 
1,2\%. Dentre as subtipologias mais abordadas temos os naturais biológicos com o maior volume de publicações, sendo seguidos pelos geológicos, hidrológicos e sociais conflitos sociais (Figura 6). É interessante notar o fato de que os biológicos sejam mais analisados do que os geológicos e os hidrológicos juntos, embora estes dois correspondam pela maior quantidade de ocorrências já registradas no Estado do Paraná.

Figura 6 - Tipos de desastres que mais foram publicados em artigos

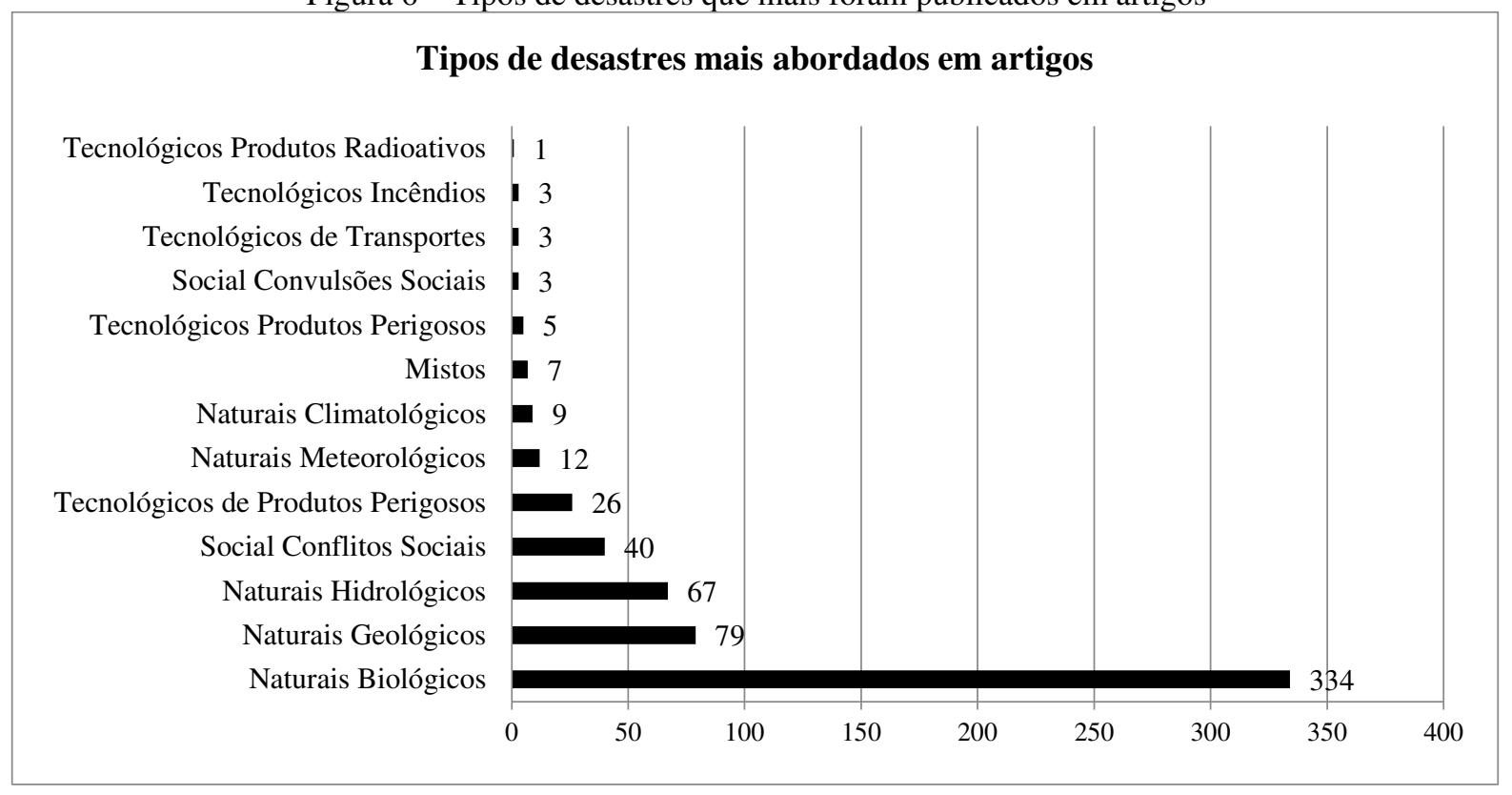

Fonte: os autores (2020)

Baseada na categorização das fases do desastre, a maioria dos artigos levantados desenvolveram trabalhos sobre a Gestão de Riscos $(90,6 \%)$ em detrimento à Gestão de Desastres $(9,4 \%)$. Quando tal informação é desagregada nas fases dos desastres, verifica-se que os trabalhos têm como foco a prevenção de eventos desastrosos, o que pode subsidiar na diminuição dos impactos decorrentes da deflagração de um desastre (Figura 7). 
Figura 7 - Publicações de acordo com as etapas da Gestão de Riscos e Desastres

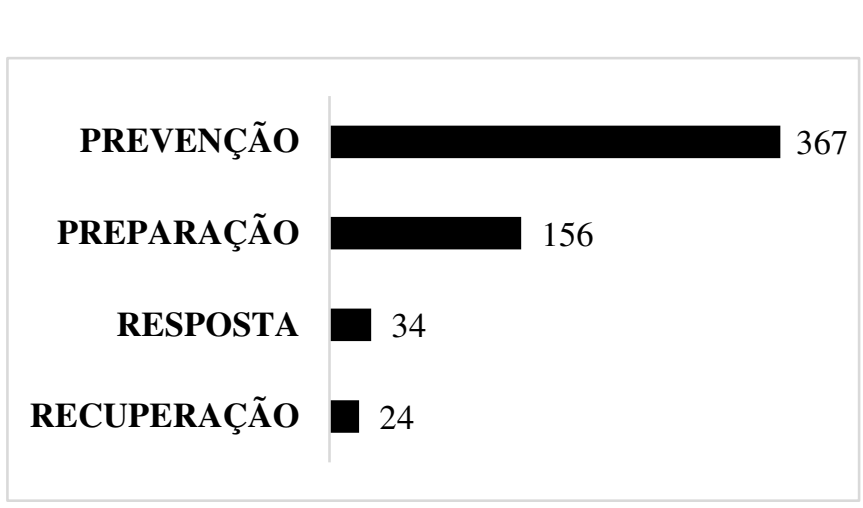

\section{Significado dos termos}

Prevenção: estudos de monitoramento do risco de desastres em uma região.

Preparação: análise de iniciativas concretas para minimizar riscos.

Resposta: propostas do que fazer imediatamente após um acidente.

Recuperação: pesquisas sobre reconstrução de áreas atingidas.

Fonte: os autores (2020)

Em relação à classificação da produção científica dos programas de pós-graduação, a maior parcela das publicações se concentrou no Qualis B1 e B2, com 23\% e 21\% respectivamente (Figura 8). É interessante notar a baixa concentração de artigos nas duas extremidades do espectro do Qualis, isto é, apenas 4\% dos artigos estão enquadrados no Qualis A1 (2\%) e Qualis C (2\%).

Figura 8 - QUALIS correspondente à classificação da produção científica dos programas de pós-graduação das universidades e/ou instituições do Paraná

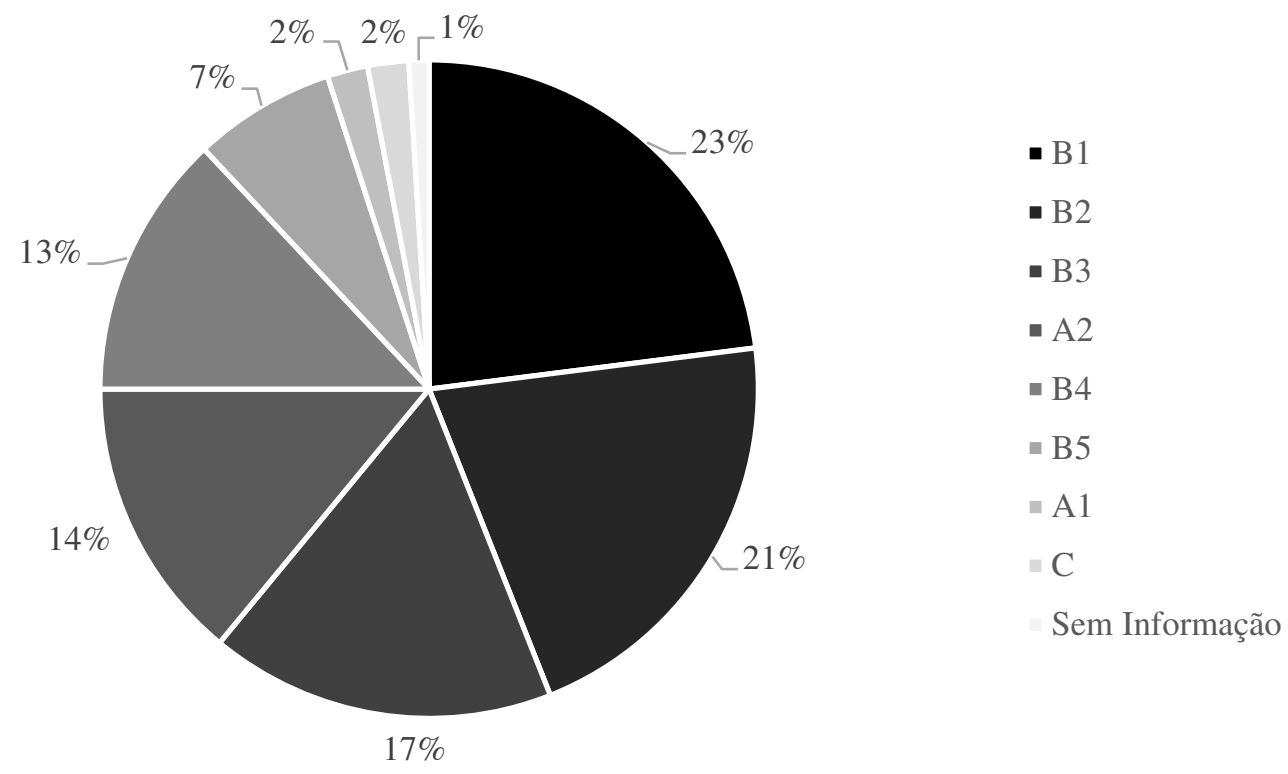

Fonte: os autores (2020) 
A técnica nuvem de palavras, que agrupa as palavras e as organiza de forma gráfica de visualização os dados linguísticos, foi realizada com as palavras-chave referidas nas publicações sobre desastres, ameaças e riscos. De 1.097 palavras que foram citadas nos 581 artigos, a palavra mais referida foi leishmaniose - repetida 56 vezes, seguida da palavra epidemiologia - mencionada 48 vezes e, em seguida, parasitoses - citada 40 vezes (Figura 9).

Figura 9 - Nuvem de palavras elaborada com base nas palavras-chave referidas nos artigos.

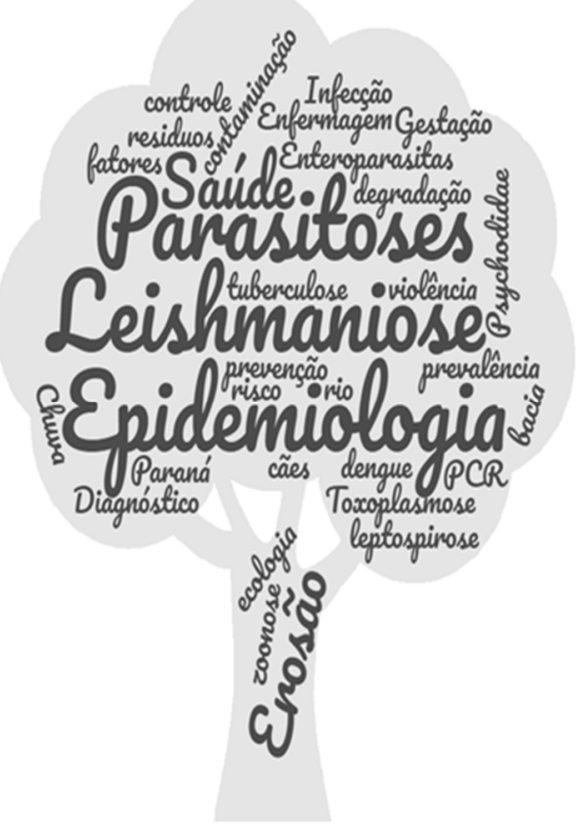

Fonte: os autores (2020)

Essa técnica de construção das nuvens visa usar tamanhos e fontes de letras diferentes conforme as ocorrências das palavras analisadas, gerando uma imagem que apresenta um conjunto de palavras, coletadas e agregadas segundo a sua frequência, sendo que a que mais aparece é alocada no centro da imagem e as demais em seu entorno, de modo decrescente (DIAS et al., 2014).

\section{ANÁLISE BIBLIOMÉTRICA}

Uma técnica utilizada em estudos dessa natureza é a bibliometria. Ela é definida como um procedimento pela qual os aspectos interconectados de comunicações escritas podem ser quantificados, podendo, inclusive, "ser utilizados para previsão e tomada de decisão" (PERES JR; PEREIRA, 2014). Dentro da bibliometria existe a análise de citações. O desenvolvimento dessa técnica representa um impulso significativo para a bibliometria. A análise de citações 
permite “[...] medir o impacto e a visibilidade de determinados autores dentro de uma comunidade científica, verificando quais 'escolas' do pensamento vigoram dentro das mesmas" (VANZ; CAREGNATO, 2003, p. 251). Ela possibilita, também, a mensuração das fontes de informação utilizadas, como o tipo de documento, o idioma e os periódicos mais citados. Ainda de acordo com eles, a utilização destes indicadores permite determinar como se dá a comunicação científica de uma área do conhecimento, e possibilita, assim, seu "mapeamento", indicando teorias e metodologias consolidadas.

Dessa forma, os dados bibliométricos foram explorados e a análise de citação foi efetuada pela ferramenta de suporte "Google Acadêmico" para a identificação das principais correntes teóricas de discussão do tema. Para tanto, o Quadro 3 mostra as publicações mais citadas acerca do tema com pelo menos 50 citações nessa base de dados.

Quadro 3 - Publicações mais citadas sobre ameaças, riscos e desastres

\begin{tabular}{|l|c|}
\hline \multicolumn{1}{|c|}{ Referência do Artigo } & $\begin{array}{c}\text { Total de } \\
\text { Citações }\end{array}$ \\
\hline $\begin{array}{l}\text { ANDRADE, S. M.; JORGE, M. H. P. M. Características das Vítimas por } \\
\text { Acidentes de Transporte Terrestre em Município da Região Sul do Brasil. } \\
\text { Revista Saúde Pública vol. 34 n. 2 São Paulo Apr. 2000. }\end{array}$ & 225 \\
\hline $\begin{array}{l}\text { NORONHA, M. G. R. C. S.; et al. Resiliência: Nova Perspectiva na Promoção } \\
\text { da Saúde da Família? Ciênc. Saúde Coletiva v. 14 n. 2 Rio de Janeiro, 2009. }\end{array}$ & 139 \\
\hline $\begin{array}{l}\text { REGIS, L. et al. Developing new approaches for detecting and preventing } \\
\text { Aedes aegypti population outbreaks: basis for surveillance, alert and control } \\
\text { system. Mem. Inst. Oswaldo Cruz vol. 103 n. 1 Rio de Janeiro, 2008. }\end{array}$ & 125 \\
\hline $\begin{array}{l}\text { BAKONYI, S. M. C.; et al. Poluição Atmosférica e Doenças Respiratórias em } \\
\text { Crianças na Cidade de Curitiba, PR. Revista Saúde Pública vol. 38 n. 5 São } \\
\text { Paulo, 2004. }\end{array}$ & 117 \\
\hline $\begin{array}{l}\text { REICHE, E. M. V. et al. Prevalência de tripanossomíase americana, sífilis, } \\
\text { toxoplasmose, rubéola, hepatite B, hepatite C e da infecção pelo vírus da } \\
\text { imunodeficiência humana, avaliada por intermédio de testes sorológicos, em } \\
\text { gestantes atendidas no período de 1996 a 1998 no Hospital Universitário } \\
\text { Regional Norte do Paraná. Rev Soc Bras Med Trop vol. 33 n. 6 Uberaba, 2000. }\end{array}$ & 100 \\
\hline $\begin{array}{l}\text { LIMA, A. P.; et al. Distribuição da Leishmaniose Tegumentar por imagens } \\
\text { de sensoriamento remoto orbital, no estado do Paraná, Brasil. Anais Bras } \\
\text { Dermatol. Vol. 77 n. 6 Rio de Janeiro, 2002. }\end{array}$ & 93 \\
\hline $\begin{array}{l}\text { MASCHIO, M. B. M.; et al. Sexualidade na terceira idade: Medidas de } \\
\text { prevenção para doenças sexualmente transmissíveis e AIDS. Revista Gaúcha } \\
\text { Enferm. (Online) vol. 32 n. 3 Porto Alegre, 2011. }\end{array}$ & 92 \\
\hline
\end{tabular}




\begin{tabular}{|c|c|}
\hline $\begin{array}{l}\text { AMSON, G. V.; HARACEMIV, S. M. C.; MASSON, M. L. Levantamento de } \\
\text { dados epidemiológicos relativos à ocorrências/surtos de doenças } \\
\text { transmitidas por alimentos (DTAS) no estado do Paraná Brasil, no período } \\
\text { de } 1978 \text { a 2000. Ciênc. Agrotec. Vol.30 n.6 Lavras, } 2006 .\end{array}$ & 88 \\
\hline $\begin{array}{l}\text { TEODORO, U. et al. Observações sobre o comportamento de flebotomíneos } \\
\text { em ecótopos florestais e extraflorestais, em área endêmica de Leishmaniose } \\
\text { Tegumentar Americana, no Norte do estado do Paraná, sul do Brasil. } \\
\text { Revista de Saúde Pública. } 1993,24 \text { (4): } 242-249 .\end{array}$ & 86 \\
\hline $\begin{array}{l}\text { SILVEIRA, T. G. V. et al. Observações sobre o diagnóstico laboratorial e a } \\
\text { epidemiologia da Leishmaniose Tegumentar no estado do Paraná, sul do } \\
\text { Brasil. Revista Soc Bras Med Trop. Vol. } 32 \text { n.4 Uberaba, } 1999 .\end{array}$ & 80 \\
\hline $\begin{array}{l}\text { ANDRADE, S. M.; JORGE, M. H. P. M. Acidentes de Transporte Terrestre } \\
\text { em cidade da Região Sul do Brasil: Avaliação da cobertura e qualidade dos } \\
\text { dados. Cadernos de Saúde Pública. } 2001,17 \text { (6): } 1449-1456 .\end{array}$ & 74 \\
\hline $\begin{array}{l}\text { FALAVIGNA-GUILHERME, A. L. et al. Prevalência de enteroparasitas em } \\
\text { horticultores e hortaliças da feira do produtor de Maringá, Paraná. Revista } \\
\text { Soc Bras Med Trop vol. } 32 \text { n.4 Uberaba, } 1999 .\end{array}$ & 73 \\
\hline $\begin{array}{l}\text { MARTINS, C. B. G.; ANDRADE, S. M. Epidemiologia dos acidentes e } \\
\text { violências entre menores de } 15 \text { anos em município da região sul do Brasil. } \\
\text { Revista Latino-Am Enfermagem vol.13 n.4 Ribeirão Preto, } 2005 .\end{array}$ & 73 \\
\hline $\begin{array}{l}\text { CEZAR, E. S.; MARZIALE, M. H. P. Problemas de violência ocupacional em } \\
\text { um serviço de urgência hospitalar da cidade de Londrina, Paraná, Brasil. } \\
\text { Cadernos de Saúde Pública. 2006, 22(1): 217-221. }\end{array}$ & 67 \\
\hline $\begin{array}{l}\text { SANTOS, S. A.; MERLINI, L. S. Prevalência de Enteroparasitoses na } \\
\text { população do município de Maria Helena, Paraná. Ciênc. Saúde coletiva } \\
\text { vol.15 no.3 Rio de Janeiro, } 2010 \text {. }\end{array}$ & 66 \\
\hline $\begin{array}{l}\text { RALISCH, R. et al. Resistência à penetração de um latossolo vermelho } \\
\text { amarelo do cerrado sob diferentes sistemas de manejo. Revista bras. Eng. } \\
\text { Agrí. Ambient. v.12 n.4 Campina Grande, } 2008 \text {. }\end{array}$ & 66 \\
\hline $\begin{array}{l}\text { BERTOL, O. J. et al. Perdas de solo e água e qualidade do escoamento } \\
\text { superficial associadas à erosão entre sulcos em área cultivada sob } \\
\text { semeadura direta e submetida às adubações mineral e orgânica. Revista Bras } \\
\text { Ciênc. Solo vol. } 31 \text { n. } 4 \text { Viçosa, } 2007 \text {. }\end{array}$ & 65 \\
\hline $\begin{array}{l}\text { CHIEFFI, P. P.; MÜLLER, E. E. Prevalência de parasitismo por Toxocara } \\
\text { canis em cães e presença de ovos de Toxocara sp no solo de localidades } \\
\text { públicas da zona urbana do município de Londrina, estado do Paraná, } \\
\text { Brasil. Revista Saúde Pública vol.10 n.4 São Paulo Dec. } 1976 .\end{array}$ & 65 \\
\hline $\begin{array}{l}\text { CASTRO, E. A.; SOCCOL, V. T.; MEMBRIVE, N.; LUZ, E. Estudo das } \\
\text { características epidemiológicas e clínicas de } 332 \text { casos de Leishmaniose } \\
\text { Tegumentar notificados na região norte do estado do Paraná de } 1993 \text { a } 1998 .\end{array}$ & 64 \\
\hline
\end{tabular}




\begin{tabular}{|l|c|}
\hline Revista Soc Bras Med Trop vol.35 no. 5 Uberaba, 2002. & \\
\hline $\begin{array}{l}\text { BERTOLINI, D. A. et al. Prevalence of serological markers of hepatitis B } \\
\text { virus in pregnant women from Paraná state, Brazil. Braz J Med Biol Res } \\
\text { vol.39 no.8 Ribeirão Preto, 2006. }\end{array}$ & 59 \\
\hline $\begin{array}{l}\text { SILVEIRA, T. G. V. et al. Aspecto epidemiológicos da Leishmaniose } \\
\text { Tegumentar em área endêmica do estado do Paraná, Brasil. Caderno Saúde } \\
\text { Pública Vol. 12. n.2 Rio de Janeiro, 1996. }\end{array}$ & 59 \\
\hline $\begin{array}{l}\text { BORTOLIERO, A. L; et al. Soroprevalência da infecção pelo vírus da } \\
\text { hepatite E (VHE) e candidatos a doadores de sangue voluntários do } \\
\text { hemocentro regional de Londrina, estado do Paraná, Brasil. Revista Inst Med } \\
\text { Trop S. Paulo vol.48 n.2 São Paulo, 2006. }\end{array}$ & 56 \\
\hline $\begin{array}{l}\text { FERREIRA, R. R. M.; TAVARES FILHO, J.; FERREIRA, V. M. Efeitos de } \\
\text { sistemas de manejo de pastagens nas propriedades físicas do solo. Semina: } \\
\text { Ciência Agrárias, Londrina, v. 31, n. 4, p.913-932, 2010. }\end{array}$ & 52 \\
\hline $\begin{array}{l}\text { PALUDO, M. L.; et al. Frequency of Toxocara infection in children attended } \\
\text { by the health public service of Maringá, south Brazil. Revista Inst. Med. } \\
\text { Trop. S. Paulo 49(6): 343-348, 2007. }\end{array}$ & 50 \\
\hline
\end{tabular}

Fonte: os autores (2020)

Dos 24 trabalhos mais citados cerca de 63\% corresponde a publicações sobre saúde, seguida pela geologia (13\%), pelo transporte terrestre $(8 \%)$ e pela violência $(8 \%)$, e pelas ciências ambientais (4\%) e ciências agrárias (4\%). Quando analisado a partir dos autores, há um total de 1.740 autores, dos quais 53\% são do gênero feminino e $47 \%$ do masculino, demonstrando um equilíbrio entre os gêneros. Em relação ao número de autores de cada artigo pode-se dizer que a característica é a publicação em dupla e em conjunto (Tabela 1). Percebese que artigos individuais têm menos frequência do que a soma dos artigos com dois ou mais autores, podendo ser um indicativo de existência de grupos de pesquisa sobre a temática.

Tabela 1 - Número de autores por artigo.

\begin{tabular}{ccc}
\hline Número de Autores & Quantidade de Artigos & Percentual (\%) \\
\hline $\mathbf{1}$ & 48 & $8 \%$ \\
$\mathbf{2}$ & 110 & $19 \%$ \\
$\mathbf{3}$ & 96 & $16 \%$ \\
$\mathbf{4}$ & 81 & $14 \%$ \\
$\mathbf{5}$ & 72 & $12 \%$ \\
$\mathbf{6}$ & 77 & $13 \%$ \\
$\mathbf{7}$ & 32 & $5 \%$ \\
$\mathbf{8}$ & 26 & $4 \%$ \\
$\mathbf{1 0}$ & 40 & $7 \%$ \\
\hline \multicolumn{3}{c}{}
\end{tabular}

Fonte: os autores (2020) 
Sobre os autores que mais publicaram sobre desastres, ameaças e riscos, destaca-se Ueslei Teodoro, mestre em saúde pública e doutor em entomologia, atuando com flebotomíneos, com 29 artigos; em segundo lugar Italmar Teodorico Navarro, doutor em epidemiologia experimental aplicada às zoonoses e atuando nos seguintes temas: toxoplasmose, zoonoses, saúde pública, febre amarela e leishmaniose, com 28 publicações; seguidos por Roberta Lemos Freire, mestre em ciência animal e doutora em epidemiologia experimental aplicada às zoonoses, atuando com epidemiologia e saneamento; e Thais Gomes Verzignassi Silveira, mestre e doutora em ciências biológicas atuando nos seguintes temas: leishmaniose tegumentar, Leishmania (Viannia) braziliensis, diagnóstico parasitológico, imunológico e molecular de leishmanioses, cada uma das autoras com 21 artigos publicados sobre o assunto; e com 17 artigos na área, Ana Lucia Falavigna Guilherme, mestre em farmácia e doutora em ciências ambientais, atuando com a toxoplasmose em gestantes, Toxoplasma gondii, Crytposporidium spp. e Giardia duodenalis. Os autores citados acima atuam todos na área da epidemiologia produzindo, na sua maioria, artigos sobre a distribuição de vetores de doenças e seu controle, abordando a área da prevenção de uma epidemia e condizendo com a classificação dos riscos de desastres biológicos.

\section{CONSIDERAÇÕES FINAIS}

Durante a obtenção dos resultados pode-se perceber que estudos sobre desastres, ameaças e riscos são pouco abordados. Apesar da sua importância o tema não esteve em evidência no período estudado. No entanto, vale salientar que a técnica da bibliometria nos faz conhecer minuciosamente as características do tema proposto. Ressalta-se que foram encontradas limitações durante a pesquisa bibliográfica, sobre a bibliometria, em relação a livros fazendo-se necessário buscar outras fontes pesquisas sobre o tema.

Não obstante, espera-se que esse tipo de limitação seja um estímulo para realização de estudos futuros sobre esse método de pesquisa, e que tenha contribuído para a prevenção e mitigação dos desastres, sejam eles naturais ou tecnológicos, uma vez que a COBRADE não contempla os sociais e mistos, assim como estava estabelecido na CODAR.

Ressalta-se, ainda, a sua importância para o monitoramento de áreas afetadas e locais de riscos, possibilitando uma melhor compreensão das vulnerabilidades, ameaças e riscos para a emissão de alertas, bem como para uma melhor comunicação de riscos, permitindo minimizar os impactos dos eventos desastrosos. 


\section{REFERÊNCIAS}

ALBUQUERQUE, A. C. Catalogação e Descrição de Documentos Fotográficos em Bibliotecas e Arquivos: uma aproximação comparativa dos códigos AACR2 e ISAD (G). Dissertação. Marília: UNESP, 2006.

ANDERSON, J. D. Organization of knowledge. In: FEATHER, J.; STURGES, P. (Eds.). International encyclopedia of information and library science. London: Routledge, 1996. p. 336-353.

BELLOTTO, H. L. Arquivos permanentes: Tratamento documental. 2 ed. Rio de Janeiro: FGV, 2004.

CEPDEC. Coordenadoria Estadual de Proteção e Defesa Civil. Ocorrências no Paraná. 2018.

DIAS M. S. A.; PARENTE J.R.F.; VASCONCELOS M.I.O., DIAS F.A.C. Intersetorialidade e Estratégia Saúde da Família: tudo ou quase nada a ver? Ciência \& Saúde Coletiva, v. 19, n. 11, Rio de Janeiro, p.4371-4382, 2014.

FREITAS, C. M. et al. Vulnerabilidade socioambiental, redução de riscos de desastres e construção da resiliência - lições do terremoto no Haiti e das chuvas fortes na Região Serrana, Brasil. Ciência \& Saúde Coletiva, v. 17, n. 6, Rio de Janeiro, 2012.

FERENTZ, L.M.S.; FONSECA, M.N.; PINHEIRO, E.G. Gestión de riesgo de desastres y los planes municipales de contingencia: estudio de caso en el municipio de Palmeira/PR. Revista Contribuciones a las Ciencias Sociales, p.1-17, outubro de 2018.

FONSECA, M.N.; GARCIAS, C.M. Comunicação de risco de inundação: instrumento fundamental da gestão de riscos de desastres. DRd - Desenvolvimento Regional em debate, vol.10, p.1139-1159, 2020

Os desafios da comunicação na redução do risco de inundação. Caminhos de Geografia, v. 22, n. 81, p. 01-14, jun./2021

FURTADO, J. R. Gestão de riscos de desastres. Florianópolis: CEPED UFSC, 2012.

GARRIDO ARILLA, M. R. Teoría e historia de la catalogación de documentos. Madrid: Editorial Síntesis, 1996.

HEREDIA HERRERA, A. Archivistica General: teoría y práctica. 5 ed. Sevilla: Diputación de Sevilla, 1991.

LANCASTER, F. W. Indexação e Resumos: teoria e prática. 2 ed. Tradução: Antonio Agenor Briquet de Lemos. Ilinois, 2003.

MEY, E. S. A. Introdução à catalogação! Brasília: Briquet de Lemos, 1995. 123p. 
MEY, E. S. A.; SILVEIRA, N. C. Catalogação no plural. Brasília, DF: Briquet de Lemos / Livros, 2009

NARVÁEZ, L.; LAVELL, A.; ORTEGA, G. La gestión del riesgo de desastres: un enfoque basado en procesos. $1^{a}$ Ed. Lima, Peru: Maiteé Flores Piérola - PULL CREATIVO S.R.L. 2009.

PERES JR., M. R.; PEREIRA, J. R. Abordagens teóricas da Gestão Social: uma análise de citações exploratória. Cadernos EBAPE.BR, v. 12, n. 2, Rio de Janeiro, 2014

PINHEIRO, E,G.; STRINGARI, D.; COVA, G.; FONSECA, M.N.; SIMIANO, L.F. Redesastre: a contribution from Paraná to the management of Disaster risk in Brazil. Global Assessment Report on Disaster Risk Reduction (GAR 2019). 2019.

.; GARCIAS, C.M.; FERENTZ, L.M.S.; FONSECA, M.N. Disaster Preparedness Indicators: an application in the state of Paraná, Brazil. Cidades, Comunidades e Territórios, Sp21, p.105-119, 2021.

SILVA, L. G.; SILVA, J. F. M. Análise da Descrição Bibliográfica do Inventário da Primeira Biblioteca Pública de São Paulo. Múltiplos Olhares em Ciência da Informação, v.5, n.1, 2015.

VANZ e CAREGNATO. Estudos de Citação: uma ferramenta para entender a comunicação científica. Em Questão, v. 9, n. 2, Porto Alegre, 2003. p. 295-307.

WORLD BANK \& UNITED NATIONS. The World Bank Annual Report 2010: year in review. The World Bank: Washington, 2010. 37 p. 